http://dx.doi.org/10.35381/racji.v5i2.746

\title{
El uso de la fuerza pública frente al derecho de resistencia
}

The use of public force against the right of resistance

\author{
Nelson Eduardo Carpio-Nata \\ nelson.carpio@psg.ucacue.edu.ec \\ Universidad Católica de Cuenca, Cuenca \\ Ecuador \\ https://orcid.org/0000-0002-0660-5954 \\ Cecilia Ivonne Narváez-Zurita \\ inarvaez@ucacue.edu.ec \\ Universidad Católica de Cuenca, Cuenca \\ Ecuador \\ https://orcid.org/0000-0002-7437-9880 \\ Juan Carlos Erazo-Álvarez \\ jcerazo@ucacue.edu.ec \\ Universidad Católica de Cuenca, Cuenca \\ Ecuador \\ https://orcid.org/0000-0001-6480-2270 \\ José Luis Vázquez-Calle \\ jlvazquezc@ucacue.edu.ec \\ Universidad Católica de Cuenca, Cuenca \\ Ecuador \\ https://orcid.org/0000-0003-4980-6403
}

Recibido: 13 de abril de 2020

Revisado: 12 de mayo de 2020

Aprobado: 27 de mayo de 2020

Publicado: 14 de junio de 2020 


\section{RESUMEN}

La investigación analiza el derecho constitucional a la resistencia de forma pacífica. De manera contraria, es necesario aplicar el uso progresivo de la fuerza por las autoridades para asegurar la integridad de las personas y bienes. Ecuador cuenta con una norma general que regula este proceder. No obstante, se requiere expedir una disposición específica para las protestas. Se propone un Reglamento a estos fines, para evitar la vulneración del derecho constitucional mencionado. En la investigación se empleó una metodología mixta de corte descriptivo, bajo un estudio doctrinal y jurídico de las variables. Se aplican encuestas a efectivos de la fuerza pública y profesionales del derecho para obtener información sobre la cuestión. Los resultados evidencian la necesidad de expedir un reglamento para usar la fuerza en el mencionado contexto. Es una investigación estratégica, importante e implica proponer una norma que garantice el ejercicio efectivo del derecho constitucional a la resistencia.

Descriptores: Derecho; resistencia a la opresión; disturbio; fuerzas armadas; no violencia. (Palabras tomadas del Tesauro UNESCO).

\section{ABSTRACT}

The investigation analyzes the constitutional right to resistance in a peaceful way. On the contrary, it is necessary to apply the progressive use of force by the authorities to ensure the integrity of people and property. Ecuador has a general rule that regulates this procedure. However, it is necessary to issue a specific provision for protests. It is intended to propose a Regulation to these ends, to avoid the violation of the mentioned constitutional right. In the investigation it uses a mixed methodology of descriptive, cut under a doctrinal and legal study of both variables. Surveys are applied to members of the public force and legal professionals to obtain information on the matter. The results show the need to issue a regulation to use force in the mentioned context. It is a strategic, important investigation and implies proposing a norm that guarantees the effective exercise of the constitutional right to resistance.

Descriptors: Law; resistance to oppression; riots; armed forces; nonviolence. (Words taken from UNESCO Thesaurus).

\section{INTRODUCCIÓN}

La presente investigación estudia el uso de la fuerza ante el derecho a la resistencia. Este se reconoce en la Constitución de la República del Ecuador y en instrumentos internaciones de derechos humanos, tanto a personas individuales como a colectivos, en 
respuesta a las acciones $u$ omisiones del poder público o de las personas naturales 0 jurídicas que puedan generar violaciones a los derechos fundamentales y que permitan demandar el reconocimiento de nuevos derechos. La manifestación del derecho a la resistencia es la protesta social de carácter pacífica.

Para analizar la problemática se debe plantear que en el contexto del ejercicio del derecho a la resistencia puede tener lugar actos violentos que desnaturalizan ese derecho y que obligan al uso de la fuerza, por parte del orden público. Este asunto resulta relevante por los cuestionamientos hechos tanto a la Policía Nacional como a las Fuerzas Armadas ecuatorianas, en las protestas sociales. Para ello, se realizará una revisión doctrinal, de la normativa jurídica y la jurisprudencia para cumplir con el objetivo de determinar que el uso progresivo de la fuerza pública no vulnera el derecho a la resistencia, cuando se producen actos violentos ocasionados por la sociedad, con el fin de velar por la seguridad de las personas, el cuidado de los bienes públicos y privados. La investigación de la problemática planteada es fundamental, teniendo en cuenta que en Ecuador existe un marco normativo para el uso progresivo de la fuerza, sin embargo, no es suficiente para el contexto de la protesta social, por sus particularidades y complejidad. Por ello, se propone una revisión de las normas a los efectos de que exista una disposición jurídica dirigida específica para estos fines que permita el empleo progresivo de la fuerza sin vulnerar el derecho a la resistencia.

La indagación resulta de gran valor y beneficio en varios órdenes. Para la fuerza pública, porque los dota de los conocimientos necesarios para no incurrir en vulneraciones al derecho humano a la resistencia. También, beneficia a la sociedad ecuatoriana porque al conocerse el fenómeno y sus normas, se genera un mayor respeto a este derecho y sus libertades por parte de las autoridades. Además, constituye un aporte académico importante al mostrar conceptos, estándares nacionales e internacionales sobre el derecho a la resistencia y el uso de la fuerza, estudios de la normativa interna y externa que permitan aclarar y enriquecer conocimientos tanto a estudiantes como a catedráticos sobre el tema investigado. 
Por lo expuesto, en los párrafos que anteceden, se plantea como problema de estudio: ¿Con el ejercicio del uso progresivo de la fuerza pública, se vulnera el derecho a la resistencia? Planteada así la interrogante, el objetivo general de este artículo es elaborar un reglamento de actuación de la fuerza pública (Policía Nacional y el Ejército ecuatoriano) que garantice el ejercicio efectivo del derecho a la resistencia en las protestas sociales con el fin de velar por la seguridad de las personas y el cuidado de los bienes públicos.

\section{Referencial teórico}

\section{El derecho a la resistencia como derecho humano}

El hombre en todas las épocas, ante ciertas condiciones y circunstancias se ha visto afectado en sus derechos o integridad; por lo que ha reaccionado rebelándose, haciendo resistencia. La (Real Academia de la Lengua Española, 2014) expone que resistencia significa contradecir, oponerse, rechazar, negativa.

El derecho a la resistencia, de forma general, para (Figueroa, 2009) es aquel que le pertenece a la comunidad y la persona física de rechazar los mandatos del poder estatal que resultan injustos. Asimismo, (Locke, 2001) afirma que nace del incumplimiento del pacto social y esto genera la defensa de derechos individuales o colectivos.

De igual forma, (Carvajal, 2001) plantea que el derecho a la resistencia es la restricción tanto de la autoridad como del Estado, el cual representa a su vez, la protección de la libertad de la comunidad; contribuye a la conservación del bienestar social común desde la justicia y del ordenamiento jurídico-político estatal, en cualquiera de sus formas.

El derecho a la resistencia es un derecho humano inherente a la persona. Acerca de esto, (Capizio, 2010) expone que los derechos se encargan de proteger a los seres humanos y a la dignidad individual; por lo que son de vital importancia el derecho a la vida, la integridad, la igualdad, no discriminación, y el derecho a la resistencia, entre otros. Por su parte, (Zambrano, 2011) considera que estos derechos expresan desde el ámbito jurídico las facultades y libertades de los hombres, representan sus aspiraciones, necesidades e intereses dirigidos a poseer una vida digna. 
En ese sentido, (Bobbio, 1991) y (Ferrajoli, 2009) aseveran que los derechos humanos son de carácter subjetivos y que el ordenamiento jurídico atribuye de forma universal a las personas con capacidad de obrar. El derecho a la resistencia se puede ejercitar individual o de forma colectiva. Es la clase de derecho humano colectivo, para (Grijalva, 2009) los titulares de estos son determinados grupos de personas.

En ese sentido, el derecho a la resistencia es una facultad que les concede la normativa a las personas y colectivos, por su propia condición humana y como todo derecho de esta naturaleza debe ser objeto de respeto y aplicación directa dentro del marco legal. Este derecho está reconocido en la norma constitucional ecuatoriana y en instrumentos internacionales de derechos humanos.

Por otro lado, (Cante \& Ortíz, 2014) aprecian el derecho humano a la resistencia como una manifestación de desobediencia civil. Lo identifican como una categoría general conocida como resistencia ciudadana. También, (González, 2007) analiza que la desobediencia civil es una herramienta para modificar una normativa o conjunto de ellas. Por tanto, es la desobediencia al derecho para lograr cierto objetivo, al respecto, la (Corte Constitucional, 2009) del Ecuador, analiza que los reclamos y activismo social en el marco del ejercicio del derecho a la resistencia o la desobediencia civil, es una versión en el seno de un Estado democrático, regido por el imperio de la ley.

En sentido general, este derecho se materializa cuando los ciudadanos salen a las calles a protestar por modificaciones ante actos y disposiciones emanadas del poder. Al hacerlo de modo incorrecto, ocasionan indisciplina y pueden colocar al Estado en situaciones de total inseguridad y emergencia. No solo tiene lugar ante decisiones políticas procedentes del poder ejecutivo, sino que se perfecciona frente a cualquier manifestación de dominación.

De esta manera, el derecho a la resistencia constituye una reacción ante una acción o acto desmedido, desproporcionado y no autorizado por el Estado, e incluso por particulares, este establece el elemento central del derecho analizado. Para (Rao, 2010) aparenta alejarse del Estado de Derecho, genera reconocer una realidad que existe fuera del derecho a través de la protesta social. Como indica (Zaffaroni, 2013) constituye un 
reclamo de derechos por vías no institucionales que muchas veces están en los límites de la legalidad, buscando que las instituciones actúen de manera correcta o que representen a sus intereses. Al respecto, (Gargarella, 2006) asevera que las protestas como manifestación del derecho a la resistencia, son quejas que realizan determinados grupos que se sienten insatisfechos por sus necesidades básicas.

El derecho examinado, como explica (Cordero, 2013), está compuesto por tres elementos fundamentales: a) la persona que hace resistencia, que es el titular del derecho, b) los obligados, que son las autoridades que tomaron la decisión, normativa o política que causó la resistencia, c) las clases de prestaciones o actitudes que se exigen a la autoridad.

El derecho estudiado se puede ejercer según (Hidalgo, 2019), de manera activa o pasiva. La primera, cuando el objetivo de la resistencia se ejecuta contra los actos emanados de un gobernador ilegítimo o que, a pesar de haber sido elegido de modo democrático, se comporta como tirano. Asimismo, (Rawls, 2006) identifica como resistencia pasiva un acto público donde no existe violencia, es político y consciente, es contrario a las normativas y se comete con la finalidad de una reforma en la ley o en los programas trazados por el gobierno.

A modo de conclusión, se puede afirmar que el derecho a la resistencia es un derecho humano y tiene carácter constitucional, al estar reconocido en la Constitución ecuatoriana. Este puede ser ejercitado, tanto por la persona individual como por la colectividad. Aparece ante cualquier mandato o decisión de orden política, social, comunitaria o de otro ámbito que implique una afectación a los derechos. Constituye una facultad de las que gozan las personas para manifestar desobediencia o negarse a cumplir una norma o decisión arbitraria proveniente del poder, público o privado.

\section{Regulación constitucional del derecho a la resistencia y reconocimiento en instrumentos internacionales de derechos humanos}

El derecho a la resistencia, como se ha dicho, es un derecho humano y tiene rango constitucional en el Ecuador. Está consagrado en el artículo 98 donde se establece: 
Los individuos y los colectivos podrán ejercer el derecho a la resistencia frente a acciones $u$ omisiones del poder público o de las personas naturales 0 jurídicas no estatales que vulneren o puedan vulnerar sus derechos constitucionales, y demandar el reconocimiento de nuevos derechos. (Constitución de la República del Ecuador, 2008, art. 98)

El artículo citado, faculta a las personas o a la colectividad a invocar el derecho de resistencia como último recurso para enfrentar decisiones arbitrarias, las que de otra manera no se podrían contrarrestar. Su objeto son los actos y omisiones derivadas del poder público o de personas naturales o jurídicas de carácter estatal que violen o puedan vulnerar derechos constitucionales y demandar que se reconozcan nuevos derechos. Este derecho constitucional como exponen (Rodas-Cordero, Erazo-Álvarez, Pinos-Jaén, \& Narváez-Zurita, 2020), se encuentra conformado por el conglomerado de derechos humanos inherentes y por esto debe ser objeto de protección y garantía.

Acerca del derecho a la resistencia, (Zaffaroni, 2013) explica que está implícito en derechos como la libertad de pensamiento, de conciencia y de religión. Estos están recogidos en los artículos 18, 19 y 20 de la (Declaración Universal de Derechos Humanos, 1948) y también en la norma constitucional ecuatoriana. De igual forma, está previsto en el Pacto Internacional de Derechos Civiles y Políticos, la Convención de los Derechos del Niño. En el sistema interamericano, se reconoce en la Convención Americana sobre Derechos Humanos y la Declaración Americana de los Derechos y Deberes del Hombre; por otro lado, el (Consejo de Derechos Humanos, 2013) reconoce su nexo, en especial, entre la libertad de asociación y la protesta; además de que otros derechos pueden ser aplicables a las protestas pacíficas.

Cabe agregar que la (Corte Interamericana de Derechos Humanos, 2017) identifica entre los estándares internacionales del derecho a la resistencia los siguientes: que se reconozca de manera pública los derechos a la reunión pacífica y a la libertad de expresión, sin que medie discriminación alguna por motivos de opinión política; los Estados deben abstenerse de exigir autorización previa para que se ejecuten las 
manifestaciones públicas $u$ otro tipo de requerimiento excesivo que dificulten su realización.

De esta manera, la (Corte Interamericana de Derechos Humanos, 2017) plantea que no deben facilitarse las manifestaciones públicas y cooperar con sus organizadores para que desempeñen su función bajo el derecho de no discriminación, abstenerse de impedir el paso, no realizar amenazas, ni emplear la justicia penal de forma arbitraria en contra de manifestantes, activistas o de aquellos que son referentes sociales o políticos por participar en la protesta social, o por ser señalados de haberla organizado, también por el hecho de que integran un grupo o institución organizadora o convocante.

Además la (Corte Interamericana de Derechos Humanos, 2017) expone que debe excluirse la participación militar y fuerzas armadas en el manejo de la protesta. Al igual que excluir el empleo de armas de fuego para el control de estas, su ocupación es una medida extrema, no realizar detenciones masivas o indiscriminadas y cumplir con las normas internas y los estándares internacionales de la materia, entre otros. No se deben realizar registros o detenciones a los participantes que dirigen una reunión, a menos que exista un peligro claro y manifiesto de violencia inminente. Se debe señalar que violar estos estándares, cuando la protesta se realiza de manera pacífica, implica vulnerar los derechos humanos y criminalizar la protesta como manifestación del derecho a la resistencia.

A pesar de lo antes expuesto, el derecho a la resistencia, como se ha planteado tiene implícitos otros derechos y se debe ejercer de forma no violenta. Sobre ello, la (Corte Interamericana de Derechos Humanos, 2019) expone que los resistentes, poseen la libertad de seleccionar la forma, el tipo, el sitio y el mensaje bajo el que se desarrollará la protesta pacífica.

A propósito del carácter pacífico del derecho a la resistencia, (Salazar, 2010) analiza que sus límites impiden que se justifiquen actos de violencia o delitos en ocasión de este; no pueden justificarse actos agresivos, en ocasión de ejercer derechos como: el de reunión, libertad de expresión y asociación, porque lo legítimo es su ejercicio pacífico. De modo que el ejercicio del derecho a la resistencia no implica que quien se sienta afectado por 
cierta ley o decisión, pueda realizar actos de violencia. "Interrumpir una calle o una ruta y menos aún dañar la propiedad ajena o incurrir en ilícitos mayores" (Zaffaroni, 2013, p.5).

Sobre los límites del derecho a la resistencia, se debe aludir al (Pontificio Consejo Justicia y Paz, 2005) quien considera que la resistencia goza de legitimidad cuando: se vulneran de forma grave, real y prolongada los derechos fundamentales y se hayan agotado todos los recursos; ante el caso de que no se provoquen desórdenes peores; que exista esperanza de éxito. Por último, cuando resulta imposible prever de manera racional, mejores soluciones al conflicto; de esta forma, el derecho a la resistencia no debe causar afectación alguna, ni menoscabar el orden legal nacional.

La (Corte Constitucional de Colombia, 2008) ratifica dentro del contenido del derecho a la resistencia, la no violencia. En relación con ello, la jurisprudencia penal ecuatoriana razona que cualquier resistencia que se realice, debe respetar las leyes, ser legítimas y pacíficas, para que sea reconocida y protegida por el ordenamiento jurídico y constitucional (Juicio No.17171-2013-0283, 2013).

De lo antes estudiado, se concluye que el ejercicio violento del derecho a la resistencia implica una respuesta coercitiva por parte del Estado. Se obliga ante circunstancias determinadas a hacer un empleo racional de su potestad coercitiva; ante ello, las instituciones vinculadas a este sector juegan un papel fundamental.

\section{Uso de la fuerza pública}

Luego de ser revisado el derecho a la resistencia, se debe emprender un análisis sobre la fuerza pública, en el ámbito doctrinario, es analizada por (Ossorio, 2000) como el grupo de agentes de la autoridad, que están armados, y por lo general uniformados que bajo la subordinación del poder público tienen como objeto esencial el mantener el orden interno. La fuerza pública para (Osse, 2006) es el conjunto de fuerzas integradas por la policía y el ejército u otros órganos que están a disposición del gobierno con la finalidad de mantener el orden, hacer respetar la ley y ejecutar las decisiones judiciales. 
La fuerza pública está conformada por la Policía y el Ejército, quienes, a su vez, se encuentran sujetas al mandato y decisión del gobierno central y fueron constituidas para garantizar el orden, asegurar el respeto a la ley y acatar los fallos emitidos por autoridades competentes. Según (Noboa, 2015) estas ejercen el monopolio de la fuerza de forma legítima, lo que supone actuar en legalidad.

La fuerza pública en el Ecuador está conformada por dos estamentos gubernamentales fundamentales, por el rol que juegan dentro del Estado: la Policía Nacional del Ecuador y las Fuerzas Armadas. Las dos fueron constituidas con la finalidad de asegurar el mantenimiento del orden, tanto interno como externo del país, deben ejecutar sus actuaciones con el respeto de la legalidad y acatar de manera irrestricta la Constitución de la República, leyes, códigos e instrumentos internacionales, que tienen como máximo jefe, al gobierno central.

Se debe señalar que el papel esencial de la fuerza pública en el país es garantizar el orden, por esto la (Constitución de la República del Ecuador, 2008), en el artículo 163 define como misión de la Policía Nacional, la atención a la seguridad ciudadana y al orden público. También se debe proteger el libre ejercicio de los derechos y la seguridad de las personas dentro del país, por tanto, la policía es la encargada de mantener la paz social, vigilar y controlar el respeto mutuo entre las personas y la vida en un ambiente pacífico. En el mismo orden de ideas, las Fuerzas Armadas conforman el componente que garantiza la seguridad del orden interno y externo; en ese sentido, el (Ministerio de Defensa Nacional, 2006) apunta la existencia del Comando Conjunto de las Fuerzas Armadas, que contribuye a la consecución y mantenimiento de los objetivos nacionales, según la planificación para tiempo de paz, de conflicto y de guerra. Las Fuerzas Armadas como parte de la fuerza pública están sujetas a organizarse, prepararse y actuar de forma mancomunada con la Policía Nacional del Ecuador cuando lo requiera la Presidencia de la República.

La finalidad de las acciones, tanto de la Policía Nacional como de las Fuerzas Armadas es respetar los derechos humanos de todo ciudadano, colaborar con la seguridad interna y la defensa militar del país como fuerza auxiliar, en específico cuando el gobierno central 
decrete el Estado de Excepción. Bajo este contexto, la fuerza pública debe actuar apegado a las normas, como indica (González-Castillo, Erazo-Álvarez, Ormaza-Ávila, \& Narváez-Zurita, 2020) para evitar que se desnaturalice la esencia del Estado, cuando ocurran actos fuera de lo común y se desestabilice el Estado.

La (Asamblea Nacional Constituyente, 2008) en el artículo 158 establece la misión de las Fuerzas Armadas están enfocadas en: defender la soberanía y la integridad territorial, por ello, los militares están obligados por ley a defender la seguridad externa del país, por vía terrestre, aérea y fluvial. También se debe señalar que bajo ciertas condiciones trabajan de manera conjunta con la Policía para mantener el orden público, la seguridad de los bienes y la integridad física de las personas.

Los órganos antes mencionados, hacen uso de la fuerza pública, bajo diferentes contextos, (González, 2006) expone que el empleo de dicha fuerza es la función de determinados miembros de un grupo para en nombre del colectivo, prevenir y reprimir la violación de las reglas que rigen el grupo, de resultar necesario, a través de intervenciones coercitivas que aluden al uso de la fuerza.

El uso de la fuerza está regida por instrumentos internacionales de derechos humanos que buscan armonizar criterios sobre su uso, entre ellos están: la Convención contra la Tortura y otros Tratos o Penas Crueles, Inhumanos o Degradantes de Naciones Unidas; el Código de Conducta para Funcionarios encargados de hacer cumplir la ley, los Principios Básicos sobre el empleo de la fuerza y de las Armas de Fuego; la Convención Interamericana para prevenir y sancionar la Tortura, entre otros.

Además, pueden hacer uso del empleo de la fuerza, las instituciones autorizadas por el Estado ecuatoriano: la Policía Nacional del Ecuador, Fuerzas Armadas, ante un grupo de manifestantes que se opone a las decisiones políticas tomadas por un gobierno. Esta se aplica cuando se protesta de forma violenta, siempre que el caso lo amerite y se respeten de forma irrestricta los derechos humanos, entre ellos, el derecho a la resistencia.

Al respecto, (Martínez, 2017) vincula el uso de la fuerza a tres elementos fundamentales: la oportunidad en que debe emplearse; el tipo y cantidad de fuerza que corresponde utilizar y la responsabilidad que debe estar presente en su uso. Otra cuestión 
fundamental, analizada por el citado autor, sobre el uso de la fuerza, es la existencia de un marco de sostenibilidad institucional, es decir, de los órganos de la fuerza pública profesional que actúen bajo los principios de legitimidad, transparencia, control y eficiencia de su actuación.

Por su lado, (Martínez, 2012) analiza las circunstancias bajo las que se puede ejecutar la fuerza pública policial: para evitar cualquier alteración del orden público y social; asegurar la convivencia armónica entre ciudadanos y Estado; aseverar el cumplimiento, respeto de los derechos individuales. Para precautelar la integridad física de las personas y sus bienes, impedir la comisión de delitos e infracciones legales y para brindar protección y auxilio a la población ante siniestros, desastres, entre otros.

A este respecto, la fuerza pública, sustentada en la responsabilidad constitucional está obligada por ley, a hacer uso de la fuerza ante el hecho de que una o varias personas quebranten los derechos de las otras, entre ellos por afectaciones a la integridad física, daños a la propiedad ajena, paralización de un servicio público entre otros. La fuerza pública de inmediato debe restablecer el orden interno y la seguridad ciudadana para asegurar el bien común, mediante el uso progresivo de la fuerza.

La Policía Nacional del Ecuador, utilizará la fuerza, cuando personas agresivas atenten contra los derechos de las otras personas. La fuerza policial, según (Amnistía Internacional, 2016) debe velar y regular las conductas de tipo individual, que atentan contra la vida, los derechos y los bienes de las personas; debe enfrentar actos que puedan generar perturbación al orden público y solo sí, se vuelven violentos, deben reprimirlos mediante el uso progresivo de la fuerza como herramienta estatal para garantizar el cumplimiento de la ley.

Luego de lo expuesto, la policía al usar la fuerza emplea varios dispositivos entregados por el Estado; su uso, en las protestas, está sujeto a características técnicas y a la circunstancia de la manifestación. Su fin es asegurar su uso progresivo y racional, según las necesidades del servicio; además se debe tomar en cuenta: la clase y las situaciones del evento a controlar; determinar el alcance y características técnicas de los dispositivos 
a utilizar, de manera que tenga la capacidad de respuesta y cobertura, proporcional a la necesidad.

Corresponde mencionar según el (Ministerio del Interior, 2015) de Perú que el contexto específico de las protestas sociales determina el nivel de empleo de la fuerza que puede ejercer el funcionario de seguridad y orden público, ya que este depende del nivel de resistencia o agresividad que muestre el intervenido y las circunstancias bajo las que tiene lugar la intervención.

En Ecuador está vigente el (Reglamento de uso legal, adecuado y proporcional de la fuerza para la Policía Nacional del Ecuador, 2014) aplicable de forma general, a cualquier acto que pueda afectar la integridad de las personas, sus derechos y bienes, sus libertades, la paz a nivel público, la seguridad ciudadana y evitar la comisión de infracciones, dentro del país. Sin embargo, la norma no especifica de forma directa como se debe actuar ante la protesta social para no vulnerar el derecho a la resistencia.

En este sentido, Ecuador necesita una disposición que regule el uso de la fuerza en este contexto cuando se presentan situaciones poco comunes e involucra a grandes cantidades de personas. Ante el ejercicio del derecho a la resistencia se dan sucesos en los que intervienen las fuerzas policiales que, de no ser pacífica, obligan al uso progresivo de la fuerza para proteger los derechos humanos de la propia fuerza pública como su vida, libertad e integridad; esto por su importancia, debe estar regulado en una norma específica y no general como está previsto en la actualidad.

Por otro lado, el (Reglamento de uso legal, adecuado y proporcional de la fuerza para la Policía Nacional del Ecuador, 2014) regula en el artículo 1 que está permitido hacer uso adecuado de la fuerza en cumplimiento de sus funciones establecidas en la Constitución e instrumentos internacionales, de forma progresiva para neutralizar y reducir el nivel de amenaza. Sobre el tema la Corte Interamericana de Derechos Humanos plantea "el uso de la fuerza puede estar justificada, por ejemplo, en la defensa propia o en la necesidad de neutralizar o desarmar a los individuos involucrados en un enfrentamiento armado". (García-Ibarra contra Ecuador, 2013, p.12) 
Lo citado, obliga a emplear la fuerza de forma progresiva para evitar cualquier vulneración de los derechos humanos, sobre esto el (Reglamento de uso legal, adecuado y proporcional de la fuerza para la Policía Nacional del Ecuador, 2014) en el artículo 11 define los niveles para el uso de la fuerza comenzando por la disuasión; verbalización; control físico; empleo de técnicas defensivas no letales y la fuerza potencial letal.

De ello, se deduce que la Policía Nacional del Ecuador y el Ejército ecuatoriano debe usar la fuerza de manera adecuada; emplearla en caso de legítima defensa o de terceros, para garantizar la seguridad en sectores estratégicos, recuperar el espacio público y ante un riesgo inminente de vulneración de derechos y garantías constitucionales de las personas.

En ese sentido, en el ámbito de las protestas sociales el uso de la fuerza implica según él (Ministerio del Interior, 2014), tener clara la función de la policía en estos actos, definir los derechos y deberes de la fuerza pública y de los ciudadanos que ejercitan el derecho a la resistencia y delimitar el alcance que tiene la actuación de la fuerza pública en las protestas sociales. Ello ha sido recalcado por la (Corte Constitucional del Ecuador. Dictamen 0005-19-EE, 2019), donde se dispone que en las protestas se haga uso de la fuerza de manera necesaria, proporcional y progresiva por parte de la Policía Nacional y las Fuerzas Armadas.

De igual forma, desde una revisión del derecho europeo y para corroborar que es necesario usar la fuerza de forma progresiva ante situaciones de violencia en el contexto del ejercicio del derecho a la resistencia el Parlamento Europea ha dictado (Resolución (2019/2569) sobre el derecho a manifestarse de forma pacífica y el uso proporcionado , 2019) en la que se reconoce que dentro de la policía, se han producido numerosas víctimas, porque actúa en condiciones difíciles, por la hostilidad de algunos manifestantes y debido a la excesiva carga de trabajo.

\section{MÉTODO}

Luego de analizados aspectos teóricos acerca del uso de la fuerza y el derecho a la resistencia, corresponde determinar la metodología empleada en el artículo para lograr 
el objetivo general de la investigación, enfocado en elaborar un Reglamento de Actuación de la Fuerza Pública que garantice el ejercicio efectivo del derecho a la resistencia en las protestas sociales, con el fin de velar por la seguridad de las personas y el cuidado de los bienes públicos y privados.

La investigación fue transversal con un carácter descriptivo, por cuanto se analizó dentro del marco del Derecho Constitucional, el derecho a la resistencia como derecho humano consagrado en la Constitución ecuatoriana, además de la revisión doctrinal y legal sobre el uso de la fuerza. Esta información se obtuvo de distintas fuentes tanto primarias como secundarias: libros, documentos, la norma constitucional, leyes, análisis jurisprudenciales, artículos científicos indexados en revistas jurídicas, periódicos, entre otros.

La investigación tuvo un enfoque mixto, con énfasis en el método cualitativo, puesto que se realizó una exhaustiva revisión bibliográfica sobre el derecho a la resistencia y el uso progresivo de la fuerza, mediante el empleo de la técnica bibliográfica-documental. Esta permitió obtener: conceptos, derechos, estándares, características, requisitos, análisis jurisprudenciales de órganos jurisdiccionales nacionales y regionales. A su vez, se aplicó el método cuantitativo con el uso de la estadística inferencial, la cual posibilitó el procesamiento de los datos obtenidos de las encuestas.

Por otro lado, se empleó el Método inductivo para llegar a conclusiones generales desde hechos particulares relacionados con el uso de la fuerza en el país ante el derecho a la resistencia. Esto permitió tomar una posición sobre el fenómeno estudiado, razonar, contrastar en la discusión teoría y práctica para lograr conclusiones acertadas; también se empleó el método analítico-sintético que posibilitó la desintegración tanto del derecho a la resistencia como del uso de la fuerza en sus partes esenciales y generó un nuevo conocimiento: el hecho de hacer uso progresivo de la fuerza no vulnera el derecho a la resistencia.

La muestra para las encuestas, determinadas para el presente trabajo se estableció en un muestreo por conveniencia, afirmado en una técnica no aleatoria y muestreo no probabilístico; donde se toman en cuenta criterios como: profesión de las personas, 
ocupación, accesibilidad y conocimiento de la materia sobre el derecho a la resistencia y uso progresivo de la fuerza. Por lo tanto, la muestra estuvo conformada por: 10 miembros de las Policía Nacional del Ecuador y 10 profesionales del derecho entre los que se encuentran expertos en el área del Derecho Constitucional, jueces de primer nivel y abogados en el libre ejercicio.

\section{RESULTADOS}

Para iniciar el análisis de los resultados, se debe explicar que la encuesta como instrumento de investigación, estuvo conformada por dos cuestionarios y se aplicó a un total de 20 personas. De ellos, 10 miembros de la Policía Nacional del Ecuador y 10 profesionales del derecho entre jueces y abogados en libre ejercicio de la profesión.

La encuesta estuvo enfocada en conocer el dominio de los encuestados sobre el derecho a la resistencia y el uso progresivo de la fuerza, en especial para obtener opiniones acerca de que si la normativa vigente en el país, sobre la materia es suficiente y, si resulta necesario que se expida un Reglamento de Actuación de la Fuerza Pública dirigido a las protestas sociales, como manifestación del ejercicio del derecho a la resistencia.

El procesamiento y análisis de la información obtenida con este instrumento, sirvió de sustento científico para identificar el problema de investigación vinculado al derecho a la resistencia ante el uso progresivo de la fuerza y la necesidad de proponer un Reglamento dirigido en específico a la protesta social. Entre las principales interrogantes realizadas a los miembros de la Policía Nacional del Ecuador, estuvieron las relacionadas con el conocimiento y dominio del Derecho Constitucional a la resistencia en el que la mayoría, correspondiente al 62,5\% de los encuestados, lo conocía. En tanto que, sobre los estándares e instrumentos internacionales acerca del derecho a la resistencia, solo el $37,5 \%$ dominaba los mismos y el $100 \%$ de los encuestados ha participado en misiones dentro del contexto de una protesta social. Este elemento es importante porque demuestra la experiencia que poseen los servidores policiales en esta clase de fenómeno social. 
Por otra parte, en la encuesta se solicitó información acerca de si el Policía, había sido víctima de actos violentos en el entorno de la protesta social respondiendo el $60 \%$ de los encuestados de forma positiva. Además, se revisó lo concerniente al equipamiento para ejercer el control del orden público dentro de ella, se manifestó como resultado, un predominio en el uso de gas con respecto a otros medios. De igual forma, se preguntó si para hacer uso de la fuerza, es necesario estar bajo una agresión física inminente por parte de los manifestantes. Esta última interrogante, fue contestada como se ilustra en la figura 1:

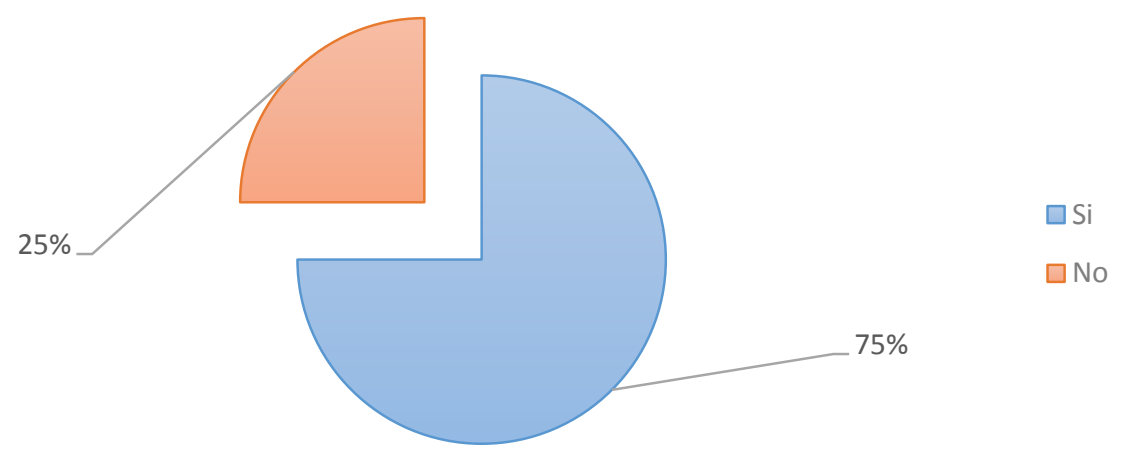

Figura 1. Norma jurídica específica para el uso legal, adecuado y proporcional de la fuerza pública. Fuente: Encuesta realizada a miembros de la Policía Nacional de Ecuador.

En este caso, se expone que la mayor cantidad de efectivos de la Policía Nacional que representan el $75 \%$ de los encuestados, proceden a hacer uso de la fuerza cuando están bajo agresión física inminente por parte de los protestantes (ver figura 1). Ello demuestra lo complejo de la situación de la protesta en la que intervienen gran cantidad de personas, mayor a la cantidad de miembros de la policía que intervienen en el control del orden. En este contexto, se pueden vulnerar derechos a los ciudadanos, así como también de los miembros de la fuerza pública, cuestión que debe estar bien determinada en la normativa. Por otro lado, se solicitó información de los encuestados, acerca de bajo que contextos se emplea el uso progresivo de la fuerza: un $37 \%$ respondió que hace uso progresivo de 
la fuerza ante la paralización del servicio público y para evitar afectaciones a la integridad, un $62,5 \%$ lo hace en la protesta social.

Corresponde señalar, que se preguntó a los encuestados si conocen el Reglamento vigente de uso legal proporcional de la fuerza para la Policía y el $100 \%$ de los encuestados admitieron conocerlo. Sin embargo, ante la interrogante de si se requiere contar con una norma jurídica específica para el uso legal y adecuado proporcional de la fuerza en la protesta social, la respuesta fue que el 100\% de los policías encuestados, coinciden en que se debe expedir una norma jurídica que regule el uso de la fuerza pública para las protestas sociales. Ello permitirá actuar con mayor claridad, más seguridad y legalidad en este contexto.

Por otro lado, fueron encuestados los profesionales del derecho y entre las interrogantes más importantes están el hecho de que el 90,9\% conoce el derecho constitucional a la resistencia y solo el 81,2\% conoce el requisito esencial para ejercitar este, que es la no violencia. Este particular preocupa, en cuanto a que los profesionales encuestados, representan o resuelven casos judiciales, relacionados con la protesta social y el no conocer este requisito, pone en riesgo el prestigio de la fuerza pública al emplear la fuerza en esta clase de protestas. De ahí la necesidad de que se plasme este requisito en una norma jurídica expedida a estos fines. De igual forma, solo el $45,5 \%$ de encuestados exponen que en los casos que ha tramitado, se ha cumplido con el requisito de no violencia para ejercitar el ejercicio del derecho a la resistencia. Ello demuestra la necesidad de hacer uso progresivo de la fuerza si las protestas se vuelven violentas. Los profesionales del derecho que fueron objeto de encuestas exponen que el $80 \%$, ha tenido en cuenta en los procesos legales, las afectaciones que puede generar el ejercicio inadecuado del derecho a la resistencia a los miembros de la fuerza pública y el 45, $5 \%$ de los encuestados, conoce las normativas nacionales acerca del uso progresivo de la fuerza.

Cabe agregar, que se les preguntó a los encuestados, si consideran que las normas vigentes para el uso progresivo de la fuerza se aplican de forma total al ejercicio del 
derecho a la resistencia y el $50 \%$ de ellos considera que no responden al contexto de las protestas sociales.

Como se observa el 90,9\% de los profesionales del derecho que están manejando la normativa para resolver procesos y representar a personas que son procesadas por actos en el contexto de la protesta, consideran que la norma vigente es insuficiente y es necesario expedir un nuevo reglamento que responda a la realidad y necesidades propias del uso progresivo de la fuerza en las protestas sociales (ver figura 2).

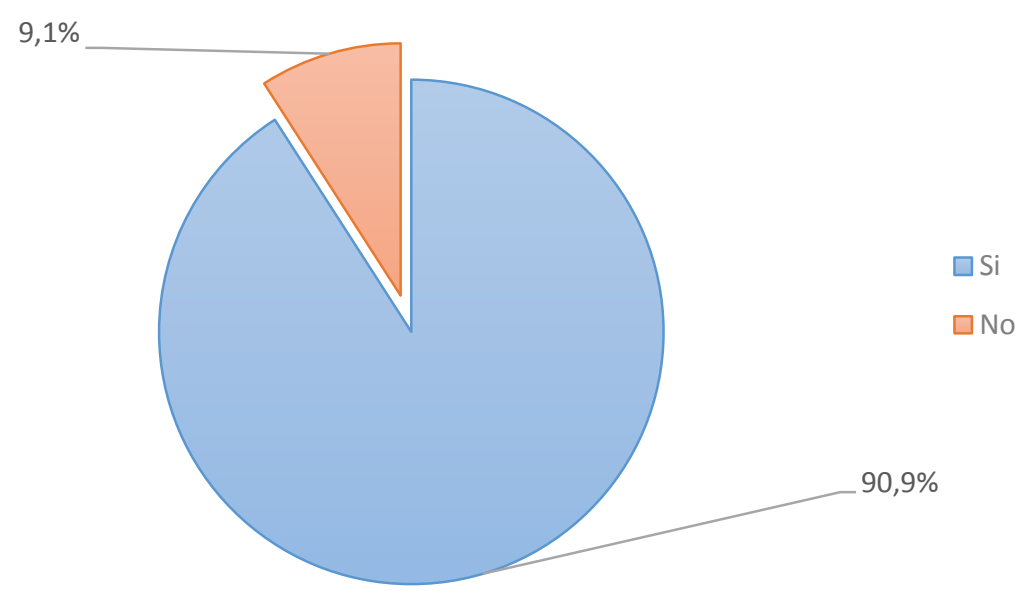

Figura 2. Necesario expedir una norma jurídica que regule el empleo progresivo de la fuerza en las protestas sociales. Fuente: Encuesta realizada a miembros de la Policía Nacional de Ecuador.

\section{PROPUESTA}

Teniendo en cuenta los resultados arrojados por las encuestas y la importancia de preservar el derecho constitucional a la resistencia y de emplear de forma racional y progresiva la fuerza, se propone expedir una propuesta de Reglamento de uso progresivo de la fuerza ante el ejercicio inadecuado del derecho a la resistencia por parte de la fuerza pública del Ecuador. Esta propuesta debe transitar por las etapas expuestas en la figura 3: 


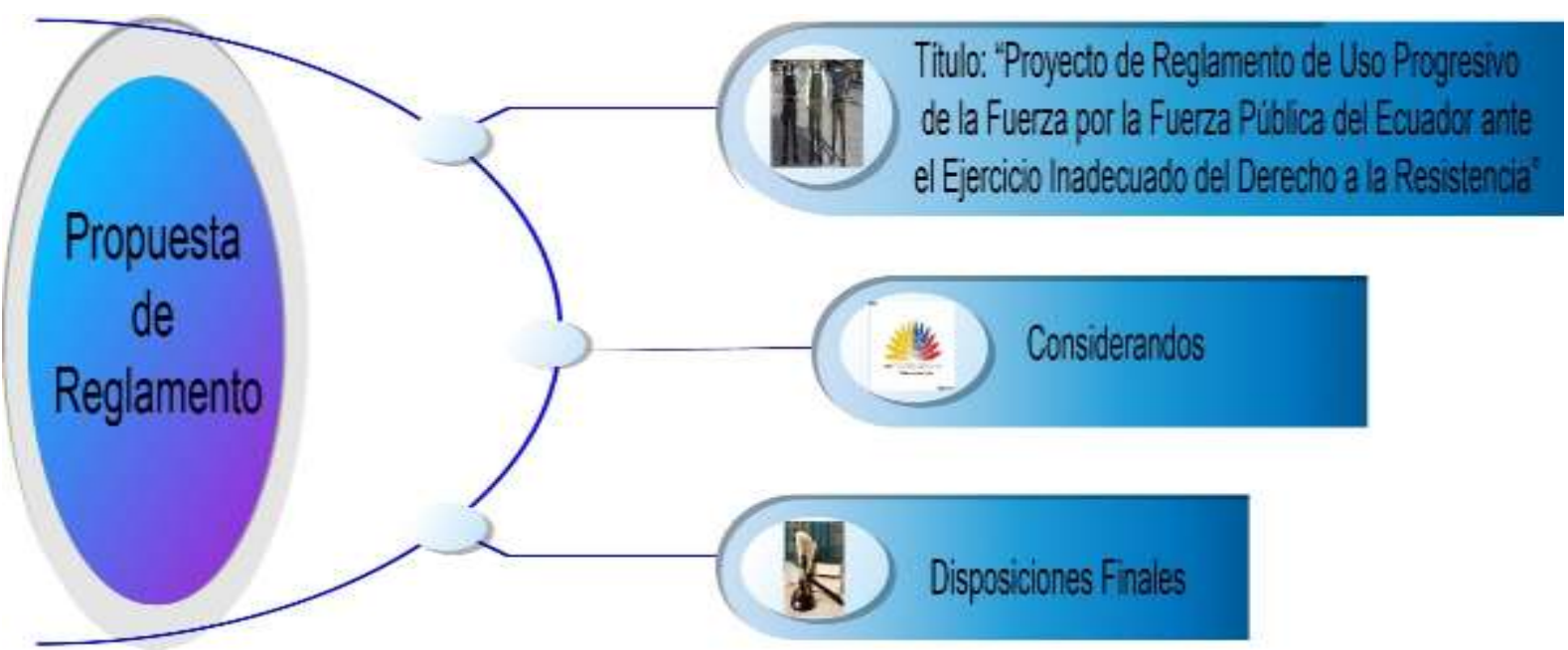

Figura 3. Esquema de las etapas para expedir la propuesta de un Reglamento

\section{Reglamento de uso legal, adecuado y proporcional de la fuerza en el contexto del} ejercicio del derecho a la resistencia por parte de la fuerza pública del Ecuador Ministra (o) de Gobierno

\section{Considerando:}

Que, el artículo 1 de la Constitución reconoce que Ecuador es un Estado constitucional de derechos y justicia, social, democrático, soberano, independiente, unitario, intercultural, plurinacional y laico.

Que, el artículo 98 de la Carta Fundamental consagra el derecho a la resistencia del que disfrutan las personas y colectivos. Por lo que se debe proteger este derecho siempre que las protestas sociales sean realizadas bajo la no violencia.

Que, el artículo 158 del texto constitucional preceptúa que las Fuerzas Armadas y la Policía Nacional son instituciones de protección de los derechos, libertades y garantías de los ciudadanos.

Que, el artículo 163 de la Carta Magna, establece que la Policía Nacional es una institución estatal de carácter civil, armada, técnica, jerarquizada, disciplinada, profesional y altamente especializada, cuya misión, es atender la seguridad ciudadana y 
el orden público y proteger el libre ejercicio de los derechos y la seguridad de las personas dentro del territorio nacional.

Que, en el país, está vigente el "Reglamento de uso legal, adecuado y proporcional de la fuerza para la Policía Nacional del Ecuador" que resulta aplicable al contexto de la protesta social. Sin embargo, por las particularidades del ejercicio del derecho a la resistencia, es muy general.

\section{Resuelve:}

Expedir el siguiente Reglamento de uso legal, adecuado y proporcional de la fuerza en el contexto del ejercicio del derecho a la resistencia por parte de la fuerza pública del Ecuador

Art. 1. Ámbito de Aplicación: el presente Reglamento es de aplicación obligatoria por parte de los servidores de la fuerza pública ecuatoriana en el contexto de la protesta social, de acuerdo a las funciones que le han sido reconocidas en la Constitución para y en virtud de instrumentos internacionales de derechos humanos y las normas infra constitucionales referidas al adecuado empleo de la fuerza para asegurar el pleno ejercicio de ese derecho y garantizar la integridad de las personas y los miembros de la fuerza pública, sus derechos y bienes dentro del territorio nacional.

Art. 2. Alcance: este Reglamento se aplica de manera exclusiva al ejercicio del derecho a la resistencia de forma violenta por parte de los protestantes dentro del territorio nacional. Se obliga a la fuerza pública a actuar con responsabilidad bajo el cumplimiento de sus obligaciones y del marco legal interno.

Esta norma jurídica no resulta aplicable a protestas sociales de carácter pacífica. El servidor que viole dicha prohibición será objeto de sanción disciplinaria en el orden administrativo, civil o penal, según corresponda.

Art. 3. Empleo del uso de la fuerza: el uso de la fuerza por parte de autoridades policiales debe ser legal, proporcionado, necesario y responsable. Su empleo debe ser de último recurso, se debe preservar la vida humana y la integridad física; bajo la condición de que su uso indiscriminado contra grupos de personas resulta contrario al 
principio de proporcionalidad. Procederá de forma excepcional cuando: los manifestantes usen armas de fuego o de determinada naturaleza contra la fuerza pública que pongan en riesgo inminente la vida y la integridad de los miembros de la Policía Nacional del Ecuador y las Fuerzas Armadas o pueda generar graves daños a la propiedad pública o privada.

El uso de la fuerza debe ser progresivo. En el contexto de la protesta social, la fuerza pública, debe evitar el contacto físico con los protestantes y emplear en primer lugar mediadores. Debe antes de su empleo, prestar atención a las personas vulnerables que puedan sufrir consecuencias fatales al emplear la fuerza, al igual que medir los efectos de las armas sobre niños, niñas y adolescentes, mujeres embarazadas, personas discapacitadas y adultos mayores o aquellas que estén bajo los efectos de drogas 0 alcohol.

La fuerza pública, debe dar prioridad a la dispersión de forma voluntaria, sin el uso de la fuerza.

\section{Art. 4. Parámetros para el empleo de la fuerza pública en el marco de la protesta} social: para usar la fuerza pública se debe estar de acuerdo con los siguientes parámetros:

a) Grado 1. Cooperación: la persona objeto de control policial cumple las indicaciones de la policía sin resistirse.

b) Grado 2. Resistencia pasiva: el protestante no obedece las indicaciones policiales, se comporta de forma indiferente ante los agentes de la fuerza pública, realiza afirmaciones con su cuerpo o responde de manera verbal y de forma negativa, no se resiste.

c) Grado 3. Resistencia activa: el protestante se opone de forma directa a la fuerza pública a través de intentos de resistencia física o evasión.

d) Grado 4. Agresión no letal: el controlado trata de agredir al agente policial, hace resistencia al control o trata de evadirlo. Sus actos no representan riesgo para la integridad personal de la autoridad. 
e) Grado 5. Agresión letal: cuando se ejecutan ataques con armas u otros medios que pueden causar afectaciones o daños graves o letales a las personas, la autoridad policial o a los bienes.

Art. 5. Actuación policial dentro de la protesta: los pasos para hacer uso progresivo de la fuerza en las protestas públicas son los siguientes:

a) Presencia policial: para lograr la disuasión mediante el uso de medios disponibles para persuadir a los infractores y advertir del posible empleo de la fuerza. Las advertencias se darán en tono imperativo, usando palabras cortas y claras.

b) Despeje: se emplea personal policial para retirar del sitio a los protestantes habilitando una vía para su salida. De no hacerlo, se hará un uso gradual de la fuerza. Se debe advertir más de una ocasión sobre todo buscar que dejen el lugar niños, niñas y adolescentes, mujeres embarazadas, adultos mayores. De no acatarse la indicación, se procede a despejar sobre la protesta violenta.

c) Dispersión: para aplicar este paso, la fuerza pública debe determinar las personas que están actuando de manera violenta y agresiva y quiénes no. Contra los primeros, deben aplicarse técnicas defensivas no letales, emplear armas incapacitantes no letales y armas de fuego con munición no letal, para neutralizar la resistencia de carácter violenta de una o varias personas.

De no obtenerse resultados, aplicando lo antes establecido, se procede empleando la fuerza de forma potencial letal, mediante la fuerza letal o armas de fuego con munición letal, para neutralizar la resistencia y los actos violentos realizados por una o varias personas, en la protesta social ilegitima, para proteger la vida del servidor de la fuerza pública o de un tercero frente a un peligro real, inminente y actual. Debe quedar constancia mediante grabaciones de este paso de la operación policial.

d) Detención: en esta etapa debe determinarse e identificarse los autores de los delitos en el marco de la protesta. Los que deben ser objeto de contravenciones se deben separar del resto de los protestantes y seguir el procedimiento pertinente, de acuerdo con la norma penal vigente. No deben ejecutarse detenciones de carácter irracionales, indiscriminadas y masivas. 


\section{Disposiciones finales}

Primera: el presente Reglamento se aplicará de conformidad con el Código de Conducta, los principios acerca del uso de la Fuerza y de Armas de Fuego por los Funcionarios Encargados de hacer cumplir la Ley, Manual de Derechos Humanos para la Policía Nacional del Ecuador, y otras disposiciones legales que resulten aplicables.

Segunda: los miembros de la fuerza pública pueden hacer empleo del equipamiento entregado por el Estado en dotación, en cualquier momento y circunstancia siempre que se cumplan con las disposiciones del presente reglamento en el contexto de la protesta pública, según las funciones reconocidas a la fuerza pública por la Constitución de la República y el ordenamiento jurídico ecuatoriano.

Tercera: se debe asegurar que los miembros de la fuerza pública reciban capacitación sobre el derecho a la resistencia y sobre las disposiciones jurídicas que se relacionen con él, al igual que sobre las regulaciones previstas en el presente Reglamento.

El presente Reglamento entrará en vigor a partir de la fecha de su suscripción, sin perjuicio de su publicación en el Registro Oficial, de su ejecución se encarga la o el Ministra (o) de Gobierno y el Comandante General de la Policía Nacional.

Dado en el Distrito Metropolitano de Quito, a 25 de mayo de 2020.

\section{DISCUSIÓN}

Luego de revisada la doctrina, la jurisprudencia, la regulación jurídica del derecho a la resistencia, el uso de la fuerza en el Ecuador y presentados los resultados obtenidos con la investigación, es posible demostrar el objetivo trazado en el trabajo consistente en elaborar un Reglamento de Actuación de la Fuerza Pública que garantice el ejercicio efectivo del derecho a la resistencia, en las protestas sociales, con el fin de velar por la seguridad de las personas y el cuidado de los bienes públicos.

De acuerdo con el objetivo planteado, el estudio evidencia que el derecho constitucional a la resistencia se manifiesta mediante las protestas sociales. Este debe ser respetado siempre y cuando se ejercite de forma pacífica, tal y como lo reconoce el ordenamiento jurídico, los instrumentos internacionales de derechos humanos y los estándares 
establecidos en esta materia. No obstante, cuando dichas protestas se tornan violentas queda demostrada la necesidad del uso de la fuerza de forma progresiva encaminada a la protección del propio miembro de la fuerza pública, la integridad de las personas y los bienes públicos y privados.

Por otro lado, queda demostrado que en Ecuador está vigente el Reglamento de uso legal, adecuado y proporcional de la fuerza para la Policía Nacional del Ecuador que tiene un amplio ámbito de aplicación y resulta muy general, partiendo de que las protestas sociales, por su naturaleza, involucran gran cantidad de personas entre las que pueden estar desde niños, embarazadas hasta ancianos. Ello refleja que la disposición vigente no es idónea para este contexto, esto exige la existencia de una norma jurídica específica y clara para aplicar el uso de la fuerza de forma progresiva en este marco, cuando las protestas pierden su carácter pacífico.

De igual forma, a través de las encuestas aplicadas en la investigación, a miembros de la Policía Nacional del Ecuador que han cumplido misión dentro de las protestas sociales y a profesionales del derecho que han tramitado asuntos relacionados con el tema, se demostró que es esencial que la fuerza pública cuente con una disposición legal que sirva de guía de actuación para emplear el uso de la fuerza ante protestas violentas. De ello se deslinda el Reglamento propuesto para asegurar en este marco, una adecuada y legítima protección a los derechos constitucionales de las personas que intervienen en ella, evitando un empleo arbitrario y desproporcionado de la fuerza.

\section{FINANCIAMIENTO}

No monetario.

\section{AGRADECIMIENTO}

A la Universidad Católica de Cuenca por apoyar la investigación. 


\section{REFERENCIAS CONSULTADAS}

Amnistía Internacional. (2016). Uso de la fuerza directrices para la aplicación de los principios básicos sobre el empleo de la fuerza y de armas de fuego por los funcionarios encargados de hacer cumplir la ley. [use of forceguidelines for the application of basic principles on the use of the force and firearms by the officials in charge of doing obey the law]. Recuperado de https://n9.cl/f12j

Bobbio, N. (1991). El tiempo de los derechos. [The time of rights]. Madrid: Sistema.

Cante, F., \& Ortiz, L. (2014). Acción política no - violenta. Una opción para Colombia. Segunda edición. [Non-violent political action. An option for Colombia. Second edition]. Bogotá: CEPI.

Capizio, J. (2010). Derechos Humanos y Ombusdman en México. [Human Rights and Ombusdman in México]. Ciudad México D.F: Unam.

Carvajal, P. (2001). Derecho a la resistencia, derecho a la revolución, desobediencia civil: Una perspectiva histórica de interpretación. La formación del derecho público y de la ciencia política en la temprana. [Right to resistance, right to revolution, civil desobediente]. Revista de Estudios Políticos, 63-101. Obtenido de https://url2.cl/ma225

Consejo de Derechos Humanos. (2013). Medidas efectivas y mejores prácticas para asegurar la promoción y protección de los derechos humanos. [Effective measures and best practices to ensure the promotion and protection of human rights. Report of the Office of the High Commissioner of the Unite. Ginebra: Consejo de Derechos Humanos.

Constitución de la República. (2008). Constitución de la República [Constitution of the republic]. Montecristi: Asamblea Nacional.

Constitución de la República del Ecuador. (2008). Constitución de la República del Ecuador [Constitution of the Republic of Ecuador]. Montecristi, Manabí, Ecuador: Registro Oficial No. 449. Obtenido de https://n9.cl/hd0a

Cordero, D. (2013). El derecho a la resistencia y la criminalización de la defensa de los derechos. [The right to resistance and the criminalization of the defense of right]. Quito: UASB. Obtenido de http://hdl.handle.net/10644/3706

Corte Constitucional, Caso No. 0001-08-AN (Corte Constitucional [Constitutional court] 8 de octubre de 2009). 
Corte Constitucional de Colombia, Sentencia T-571/08 (Corte Constitucional de Colombia [Constitutional Court of Colombia] 6 de abril de 2008).

Corte Constitucional del Ecuador. Dictamen 0005-19-EE, Dictamen 0005-19-EE (Corte Constitucional del Ecuador. Dictamen 0005-19-EE [Constitutional Court of Ecuador. Opinion 0005-19-EE] 7 de octubre de 2019).

Corte Interamericana de Derechos Humanos. (2019). Protesta y Derechos Humanos. San José: OEA.

Corte Interamericana de Derechos Humanos. (11 de abril de 2017). www.oas.org. Recuperado el 23 de noviembre de 2019, de www.oas.org: https://www.oas.org/es/cidh/prensa/comunicados/2017/044.asp

Declaración Universal de Derechos Humanos. (1948). Declaración Universal de Derechos Humanos [Universal Declaration of Human Rights]. París: ONU.

Ferrajoli, L. (2009). Los fundamentos de los derechos fundamentales. [The foundations of fundamental rights]. Madrid: Trotta.

Figueroa, M. (2009). Aspectos de la protección del domicilio en el derecho español. Derecho a la resistencia [ Aspects of home protection in Spanish law. Right to resistance]. Madrid: Edisofer S.L.

García Ibarra contra Ecuador, Caso 11.576 (Corte Interamericana de Derechos Humanos 10 de julio de 2013, p.12).

Gargarella, R. (2006). El derecho a la protesta social. Revista Derecho y Humanidades No. $12,142-151$.

Gargarella, R. (2006). El derecho a la protesta social. Revista Derecho y Humanidades No. 12. [Law and Humanities Magazine No. 12], 142-151. doi:10.5354/07192517.2011.16204

González, E. (2006). Sobre el concepto de represión [On the concept of repression]. Revista de Historia Contemporánea № 6, 15-41.

González, F. (2007). Estudio de Filosofía del Derecho. Tercera edición. [Study of Philosophy of Law. Third edition]. Tenerife: Universidad de la Laguna. 
González-Castillo, S. L., Erazo-Álvarez, J. C., Ormaza-Ávila, D. A., \& Narváez-Zurita, C. I. (20 de enero de 2020). www.fundacionkoinonia.com.ve. Recuperado el 5 de mayo de 2020, de www.fundacionkoinonia.com.ve: http://dx.doi.org/10.35381/racji.v5i8.578

Grijalva, A. (2009). ¿Qué son los Derechos Colectivos?”. Los Derechos Colectivos. Hacia una efectiva comprensión y protección. [What are Collective Rights?". Collective Rights. Towards an effective understanding and protection]. Quito: Ministerio de Justicia y Derechos Humanos.

Hidalgo, G. (2019). El Derecho de Resistencia Práctica de la acción resistente en Ecuador y sus límites conceptuales. [The Right of Practical Resistance of resistant action in Ecuador and its conceptual limits]. Quito: CEP. Obtenido de https://url2.cl/je6WV

Juicio No. 17171-2013-0283, Juicio No. 17171-2013-0283 (Tribunal de Garantías Penales Noveno de Pichincha [Judgment No. 17171-2013-0283] 4 de septiembre de 2013).

Locke, J. (2001). Ensayo sobre gobierno civil. [Essay on civil government]. Madridr: s Aguilar.

Martínez, F. (2017). Uso de la fuerza [Use of force]. Santiago de Chile: Universidad de Chile.

Martínez, O. (2012). El desafío de mejorar la Seguridad Pública [ The challenge of improving Public Safety]. Latinoamericana de Seguridad, 2-13.

Ministerio de Defensa Nacional. (2006). Libro Blanco e la Defensa Nacional - Las Fuerzas Armadas [ White Paper on National Defense - The Armed Forces]. Quito: Ministerio de Defensa Nacional.

Ministerio del Interior. (2014). Doctrina Policial de la República del Ecuador [Police Doctrine of the Republic of Ecuador]. Quito: Ministerio del Interior.

Ministerio del Interior. (2015). Comentarios, críticas y propuestas respecto del proyecto de Ley que regula el empleo de la fuerza por parte de la Policía Nacional del Perú [Comments, criticisms and proposals regarding the draft Law that regulates the use of force by the National Police. Lima: Ministerio del Interior.

Noboa, E. (2015). Doctrina del orden Público [Public order doctrine] México D.F: UNAM.

Osse, A. (2006). Entender la labor policial. Recursos para activistas de derechos humanos [Understand police work. Resources for human rights activists]. Madrid: Amnistía Internacional. 
Ossorio, M. (2000). Diccionario de ciencias jurídicas, políticas y sociales. tercera Edición [Dictionary of legal, political and social sciences. third edition]. Montevideo: Obra Grande.

Pontificio Consejo Justicia y Paz. (2005). Compendio de la doctrina social de la iglesia [ Compendium of the social doctrine of the church]. Roma: Pontificio Consejo.

Rao, R. (2010). Protesta del tercer mundo. Entre el hogar y el mundo. [Third world protest. Between home and world]. New York: Oxford University Press. Obtenido de https://url2.cl/JTD6V

Rawls, J. (2006). Teoría de la Justicia. Sexta edición. [Theory of Justice. Sixth edition]. Cambridge: The Belknap Press of Harvard University Press.

Real Academia de la Lengua Española. (2014). Diccionario de la de la Lengua Española. [Dictionary of the Spanish Language]. Madrid: Espasa.

Reglamento de uso legal, adecuado y proporcional de la fuerza para la Policía Nacional del Ecuador. (2014). Reglamento de uso legal, adecuado y proporcional de la fuerza para la Policía Nacional del Ecuador [Regulation of legal, adequate and proportional use of force for the National Police of Ecuador]. Quito: Ministerio del Interior.

Resolución (2019/2569) sobre el derecho a manifestarse de forma pacífica y el uso proporcionado. (2019). Resolución (2019/2569) sobre el derecho a manifestarse de forma pacifica y el uso proporcionado [Resolution (2019/2569) on the right to demonstrate peacefully and the proportionate use of force] de la fuerza. Bruselas: Parlamento Europeo.

Rodas-Cordero, D., Erazo-Álvarez, J. C., Pinos-Jaén, C. E., \& Narváez-Zurita, C. I. (1 de febrero de 2020). www.fundacionkoinonia.com.ve. Recuperado el 15 de mayo de 2020, de www.fundacionkoinonia.com.ve: htpp://dx.doi.org/10.35381/racji.v5i1

Salazar, D. (2010). El derecho a la protesta social en Ecuador [The right to social protest in Ecuador]. Quito: FLACSO.

Zaffaroni, E. (2013). Derecho Penal y protesta social. [Criminal law and social protest]. Pensamiento Penal, 1-24. Obtenido de https://url2.cl/Jwv1Q

Zambrano. (2011). Del Estado constitucional neo constitucionalismo. [From the neoconstitutional constitutional state]. Guayaquil: Edilexa S.A. 
Iustitia Socialis. Revista Arbitrada de Ciencias Jurídicas.

Año V. Vol. V. №2. Edición Especial. 2020-II

Hecho el depósito de Ley: FA2016000064

ISSN: 2542-3371

FUNDACIÓN KOINONIA (F.K). Santa Ana de Coro, Venezuela

Nelson Eduardo Carpio-Nata; Cecilia Ivonne Narváez-Zurita; Juan Carlos Erazo-Álvarez; José Luis Vázquez-Calle

(C2020 por los autores. Este artículo es de acceso abierto y distribuido según los términos y condiciones de la

licencia Creative Commons Atribución-NoComercial-Compartirlgual 4.0 Internacional (CC BY-NC-SA 4.0)

(https://creativecommons.org/licenses/by-nc-sa/4.0/). 